\title{
Involvement of breast cancer stem cells in tumor angiogenesis
}

\author{
YU WANG ${ }^{1 *}, \mathrm{CHEN} \mathrm{LI}^{1 *}$, YUQIANG LI ${ }^{1}$ and ZHITU ZHU ${ }^{2}$ \\ ${ }^{1}$ Biobank; ${ }^{2}$ Department of Oncology, The First Affiliated Hospital of Jinzhou \\ Medical University, Jinzhou, Liaoning 121000, P.R. China
}

Received November 19, 2016; Accepted September 5, 2017

DOI: $10.3892 / \mathrm{ol} .2017 .7238$

\begin{abstract}
The aim of the present study was to investigate the role of breast cancer stem cells (BCSCs) in the angiogenesis of breast cancer tumors. The expression levels of mutant p53, cluster of differentiation (CD)31, vascular endothelial factor (VEGF), in addition to human epidermal growth factor (HER)2, were detected in the blood vessels of human breast cancer (BC) tissue samples. CD $44^{+} / \mathrm{CD} 24^{-/ \text {low }}$ cells were selected from single-cell suspensions of $\mathrm{BC}$ tissues to assess the expression of CD31 and CD105, in addition to the ability of these cells to metabolize acetylated low-density lipoprotein (Ac-LDL). Furthermore, vascular-like structures were observed histologically. Mutant p53, CD31 and VEGF were all expressed in these tissues. $\mathrm{CD} 44^{+}$cells comprised $7.5 \pm 2.6$ and $94.3 \pm 4.7 \%$ of the cell population prior to and following sorting, respectively. CD $24^{+}$cells comprised $48.2 \pm 9.4$ and $4.3 \pm 4 \%$ of the cell population prior to and following sorting, respectively. A low proportion of $\mathrm{CD} 24^{+}$cells corresponded to a high proportion of $\mathrm{CD} 24^{-/ \text {low }}$ cells. The percentages of $\mathrm{CD} 105^{+}$and $\mathrm{CD} 31^{+}$glomus cells in the mammary gland were $4.5 \pm 0.9$ and $6.2 \pm 1.3 \%$, respectively, and following passaging for three generations, these increased to $79.6 \pm 9.3$ and $84.1 \pm 10.7 \%$, respectively $(\mathrm{P}<0.05)$. Cells were cultured using an endothelial cell culture system, and they internalized DiL-Ac-LDL. Here, vascular endothelial cells formed vascular-like structures, whereas the control group demonstrated no such structures. Overall, the results suggest that BCSCs-derived endothelial cells may contribute to tumor angiogenesis.
\end{abstract}

\section{Introduction}

Breast cancer $(\mathrm{BC})$ is one of the most common malignancies in women, and its incidence is the second highest in the world $(1,2)$.

Correspondence to: Dr Zhitu Zhu, Department of Oncology, The First Affiliated Hospital of Jinzhou Medical University, 2 People's Street, Jinzhou, Liaoning 121000, P.R. China

E-mail: zhituzhu@126.com

*Contributed equally

Key words: breast cancer, breast cancer stem cells, angiogenesis, endothelial cells, tumor stem cells
Despite various treatment methods, recurrence and metastasis are major obstacles for BC treatments (3). Studies have shown that about $40 \%$ of BC patients have experienced recurrence, and about $60-70 \%$ of patients display distant metastasis (4). Like normal human organs, tumors have a small number of primitive stem cells that have high proliferation, self-renewal, and differentiation potential. Moreover, these stem cells can be resistant to chemoradiotherapy. All of these characteristics are similar to those of normal stem cells, so cancer can be considered a type of stem cell disease. These tumor cells are termed cancer stem cells or tumor stem cells (CSCs or TSCs) $(5,6)$. These features of breast cancer stem cells (BCSCs) are also a major reason for the recurrence and distant metastasis of tumors following conventional therapies (7).

The formation of a vascular network is extremely important for tumor growth and metastasis $(8,9)$. If there are no blood vessels that can provide adequate nutrients for tumor cells, the tumor volume cannot exceed 2-3 $\mathrm{mm}^{3}$, and organ structures and functions will also be adversely affected $(10,11)$. As endothelial cells are necessary to form blood vessels, no clinically detectable tumors and subsidiary blood vessels will form in the absence of endothelial cell proliferation (12). Therefore, anti-tumor angiogenesis therapies are currently of great interest in the field of cancer treatment research.

Tumor angiogenesis can be functionally divided into vasculogenesis and angiogenesis $(13,14)$. Vasculogenesis refers to the process of differentiation and proliferation of endothelial progenitor cells (EPCs) at tumor sites. Angiogenesis refers to endotheliosis and the formation of new blood vessels at or around tumor sites using the original blood vessels as a template (15). Some studies have shown that bone marrow-derived EPCs in adults are involved in the formation of new blood vessels, which challenges current models in which angiogenesis only occurs during embryonic development. Additional studies have shown that EPCs also participate in the regeneration, repair, and angiogenesis of the heart, brain, and peripheral vessels (16). Tumors are typically rich in new blood vessels, so researchers have begun to study whether EPCs are involved in tumor angiogenesis. It has been found that many patients with cancer exhibit significantly increased numbers of EPCs in the peripheral blood circulation. As the disease progresses, EPCs increase as well. This suggests that EPCs may be involved in tumor angiogenesis. Subsequent animal experiments also revealed evidence for the contribution of EPCs to angiogenesis in primary and metastatic tumors. This may be an important reason for the poor outcomes associated with anti-angiogenic drugs (17). 
During the initiation and development of BC, endothelial cells from different sources participate in the process of BC tumor angiogenesis. This includes the proliferation of local microvascular endothelial cells and endothelial cells circulating in the bone marrow. EPCs may also participate in BC angiogenesis. Therefore, we hypothesize that endothelial cells derived from BCSCs may contribute to angiogenesis in BC.

\section{Materials and methods}

Sources of tissue samples. In total, 13 clinical BC tissue samples were collected from $\mathrm{BC}$ patients admitted to and diagnosed at the Clinical Biological Sample Center of the First Affiliated Hospital of Jinzhou Medical University from January 2015 to May 2015. No treatments were performed before surgery, and all patients received and signed the informed consent before sample collection. Eight BC tissue specimens were successfully dissociated into single-cell suspensions, but five specimens failed to dissociate. This study was approved by the ethics committee of the First Affiliated Hospital of Jinzhou Medical University. Eight specimens were successfully isolated single cell suspension of BC, but 5 specimens failed.

Collection of BC tissue samples. Specimens were obtained in the operating room. Each BC tissue sample was collected in such a way that it did not affect the pathological diagnosis. Individual samples were placed in sterile containers containing sterile PBS and streptomycin (500 U/ml) (Gibco, USA), and quickly delivered to the central laboratory within $1 \mathrm{~h}$. Each specimen was divided into two parts. One part was used to prepare the single-cell suspension, and the other part was embedded and processed for paraffin sectioning.

Immunohistochemical staining. Sections were deparaffinized and hydrated according to routine immunohistochemical procedures. After washing three times with PBS, sections were blocked with normal serum blocking solution for $15 \mathrm{~min}$. Subsequently, $100 \mu \mathrm{l}$ of diluted primary antibody was carefully added dropwise onto the slides (Santa Cruz, USA), and incubated overnight in humid boxes at $4^{\circ} \mathrm{C}$. After washing three times with PBS, goat anti-rabbit secondary antibody was added and incubated for $15 \mathrm{~min}$ at room temperature. After washing three times with PBS, HRP-labeled streptavidin was added and incubated for $10 \mathrm{~min}$ at room temperature. Slides were then washed with PBS and DAB staining was performed. The colorimetric development reaction was stopped when the background turned slightly brown. Sections were counterstained with hematoxylin for $3 \mathrm{~min}$, treated with $1 \% \mathrm{HCl}$ alcohol for $30 \mathrm{sec}$, and rinsed in tap water for $10 \mathrm{~min}$. Sections were air-dried, mounted with neutral gum, and visualized using light microscopy. Samples were examined and interpreted by two or more pathologists.

Immunofluorescence staining. Frozen sections were placed at room temperature for $30 \mathrm{~min}$, fixed in acetone at $4^{\circ} \mathrm{C}$ for $10 \mathrm{~min}$, washed three times with PBS buffer, and incubated with $3 \%$ $\mathrm{H}_{2} \mathrm{O}_{2}$ for $10 \mathrm{~min}$ to eliminate endogenous peroxidase activity. After washing three times, appropriately diluted primary antibody was added and incubated overnight at $4^{\circ} \mathrm{C}$. The next day, samples were rinsed with PBS and incubated at room temperature for $20 \mathrm{~min}$ with reagent 1 of the kit. Sections were rinsed and then incubated at room temperature for $30 \mathrm{~min}$ with reagent 2 of the kit. After rinsing, AEC coloration was developed, followed by re-staining. Slides were mounted with neutral gum and microscopy was performed. The histological sections were subsequently analyzed by two or more pathologists.

\section{HER-2 fluorescent in situ hybridization (FISH)}

Immunofluorescence. Sections were baked at $56^{\circ} \mathrm{C}$ overnight, and then placed in xylene at room temperature for $10 \mathrm{~min}$. Sections were rinsed and then dehydrated for $5 \mathrm{~min}$ in absolute ethanol. These steps were repeated twice, and sections were then air-dried at room temperature. Next, sections were immersed in pretreatment solution at $80^{\circ} \mathrm{C}$ for $10 \mathrm{~min}$, and rinsed in ultrapure water for $3 \mathrm{~min}$. The residual liquid was aspirated, and the sections were placed into protease solution at $37^{\circ} \mathrm{C}$ for $10 \mathrm{~min}$. This was followed by gradient dehydration, air-drying at room temperature, incubation with an Abbott probe (the hybridization area, Abbott, USA), mounting, overnight hybridization using the ThermoBrite hybridization instrument, DAPI staining, and observation under a fluorescence microscope.

Interpretation of the results. A ratio $<2$ indicated that the $H E R 2 / N E U$ gene was not expressed. A ratio $\leq 2$ indicated that the $H E R 2 / N E U$ gene was expressed. If the ratio was near the critical range of 1.8-2.2, 20 more nuclei were counted to calculate the ratio. Alternatively, conclusions were made using another counting method in combination with clinical results.

Isolation and culture of BCSCs. BC tissue samples were cut into small pieces, placed in sterile centrifuge tubes, and digested for 30 min with $0.05 \%$ type II collagenase at $37^{\circ} \mathrm{C}$ in a sterile incubator. The suspension was collected after 5 min of centrifugation at $1000 \mathrm{rpm}$ and filtered. Samples were then incubated with DMEM supplemented with $10 \%$ fetal bovine serum and $1 \%$ mycillin dual antibodies. The single-cell suspensions of BC tissues were then examined for the expression of CD44 and CD24 using flow cytometry. CD $44^{+} / \mathrm{CD} 24^{- \text {/low }}$ cells were inoculated into DMEM/F12 serum-free medium containing $20 \mu \mathrm{g} / \mathrm{l}$ EGF, $20 \mu \mathrm{g} / \mathrm{lbFGF}$, and 2\% B27. The growth of BCSCs was observed, and the medium was changed 3 days after starting the culture.

Culture and functional testing of endothelial cells. $\mathrm{CD} 44^{+} / \mathrm{CD} 24^{-/ \text {low }}$ cells were cultured in the stem cell culture system for 1-2 weeks. After mammary gland glomus cells formed in the culture plate, they were collected and digested into single-cell suspensions. Trypan blue staining was performed to count living cells, and a special culture medium for endothelial cells (EGM-2) was used to promote proliferation and observe cell growth. The 3rd-generation endothelial cells were collected and stained with DiL-Ac-LDL. The concentration of DiL-Ac-LDL was $10 \mathrm{~g} / \mathrm{ml}$, the endothelial cells were incubated at a temperature of $37^{\circ} \mathrm{C}$ for $4 \mathrm{~h}$, then washed with PBS. The cells were fixed with $4 \%$ paraformaldehyde fixed cells for $10 \mathrm{~min}$ and to take photographed by fluorescence microscope. Positive cells were considered to be undergoing differentiation. Adipocytes were used as a control group.

Detection of angiogenesis. A 24-well plate was coated with $300 \mathrm{ml}$ Matrigel (BD, USA) and gently shaken. The gel was allowed to solidify at $37^{\circ} \mathrm{C}$. The 3 rd-generation endothelial cells 
A

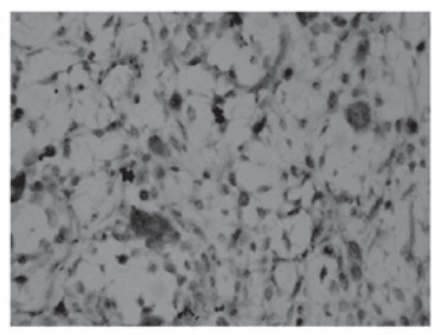

B

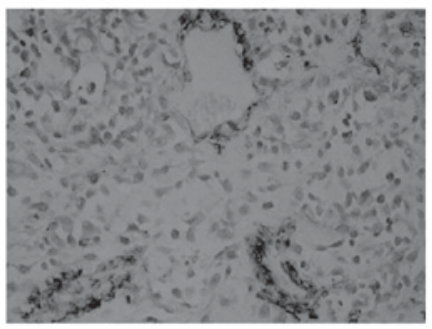

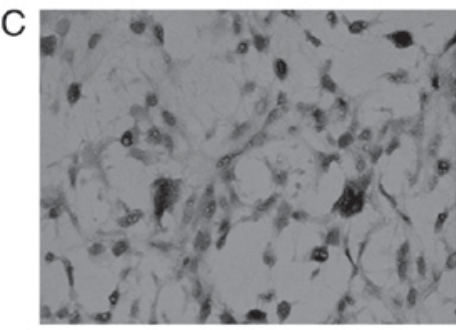

Figure 1. Immunohistochemical staining results of vessels in BC specimens (x100). (A) CD31; (B) VEGF; (C) Mutant P53.

A

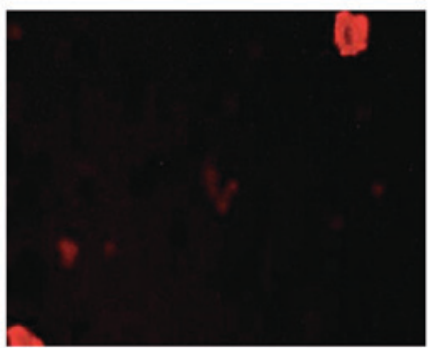

B

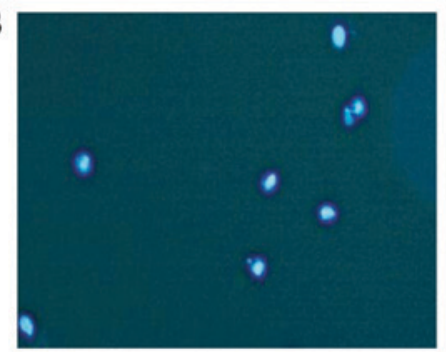

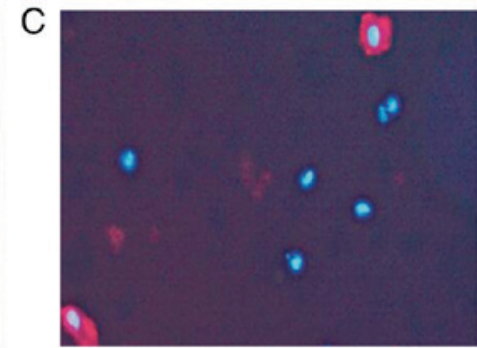

Figure 2. Immunofluorescence staining results of vessels in BC specimens (x100). (A) CD31; (B) DAPI; (C) dual staining of CD31+DAPI.
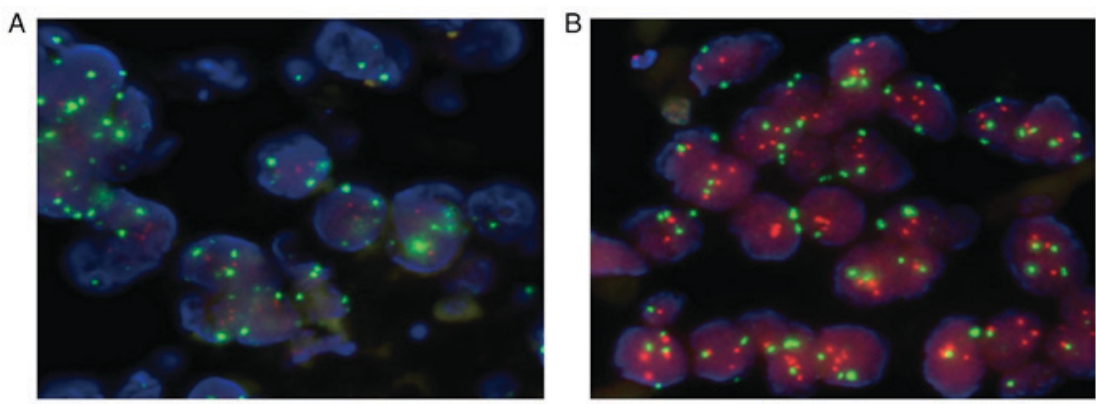

Figure 3. FISH results of Her-2 (x100). (A) Her-2-negative; (B) Her-2-positive.

harvested from the endothelial cell culture system were then digested with trypsin until the cell edges became round. After discarding the supernatant, the cells were repeatedly pipetted in the medium until they formed a single-cell suspension. The suspension was then inoculated into the 24-well plates. Adipocytes were used as a control. Angiogenesis was assessed microscopically $24 \mathrm{~h}$ after starting the culture.

Detection of $C D 105$ and $C D 31 . \mathrm{CD}_{4} 4^{+} / \mathrm{CD} 24^{- \text {low }}$ cells and the 3rd-generation endothelial cells were harvested. Specimens were prepared and the expression of CD105 and CD31 was assessed by flow cytometry.

Statistical analysis. SPSS 20.0 software was used to analyze the experimental results. Data are expressed as the mean \pm standard deviation $\left(x^{-} \pm \mathrm{s}\right)$. The intergroup comparison was performed by using single-factor analysis of variance, and $\mathrm{P}<0.05$ was considered statistically significant.

\section{Results}

Expression of CD31, VEGF, and mutant p53 in BC tissue. Expression of CD31, VEGF, and mutant p53 was observed in paraffin sections of BC tissue samples (tan). Expression was enriched in cells lining the vessel lumen or in vascular spheres (Fig. 1). Immunofluorescence showed that CD31 and DAPI co-localized intravascularly in the BC tissue specimens (Fig. 2).

Expression of HER2 in BC tissue. Among the 13 specimens, HER2-positive cells were detected in 4 of 9 cases. Red FISH signal indicated the localization of HER2, and green FISH signal stained CSP on chromosome 17 (Fig. 3).

Detection of $\mathrm{CD} 44^{+} / \mathrm{CD} 24^{- \text {llow }}$ cells. Isolated BCSCs were subjected to flow cytometry after immunomagnetic sorting to quantify $\mathrm{CD} 44^{+} / \mathrm{CD} 24^{-/ \text {low }}$ cells. This showed that CD $44^{+} / \mathrm{CD} 24^{-/ \text {low }}$ cells comprised $7.5 \pm 2.6$ and $94.3 \pm 4.7 \%$ of the total cell suspension before and after immunomagnetic sorting, respectively (Fig. 4A and B). CD24+ cells constituted $48.2 \pm 9.4$ and $4.3 \pm 1.6 \%$ of the total cell suspension before and after immunomagnetic sorting, respectively. This indicated that lower the proportion of CD24+ cells observed, higher was the proportion of CD24-low cells (Fig. 4C and D).

Isolation and culture of BCSCs. Isolated CD $44^{+} / \mathrm{CD} 24^{-/ \text {low }}$ mononuclear cells were round in shape, and they were easily 

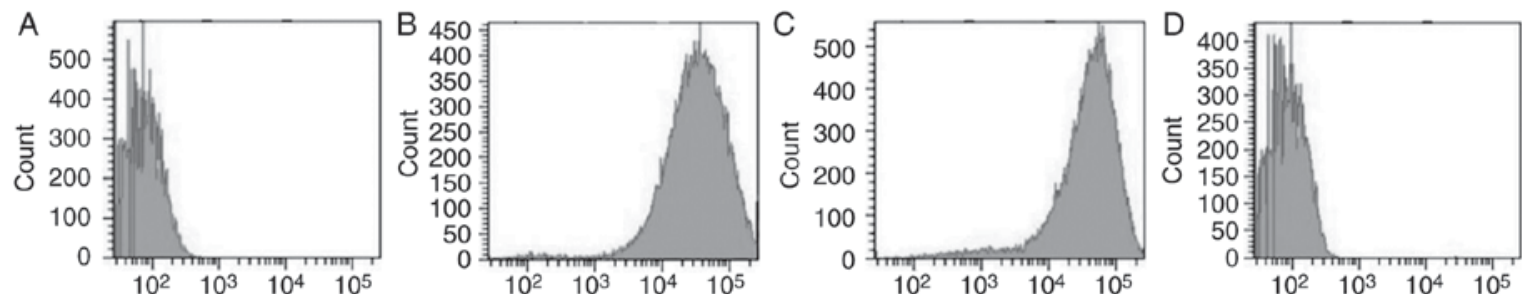

Figure 4. $\mathrm{CD} 44^{+}$and $\mathrm{CD} 24^{+}$cell ratios before and after sorting. (A) CD44+ before sorting; (B) CD $44^{+}$after sorting; (C) $\mathrm{CD} 24^{+}$before sorting; (D) $\mathrm{CD} 24^{+}$after sorting.
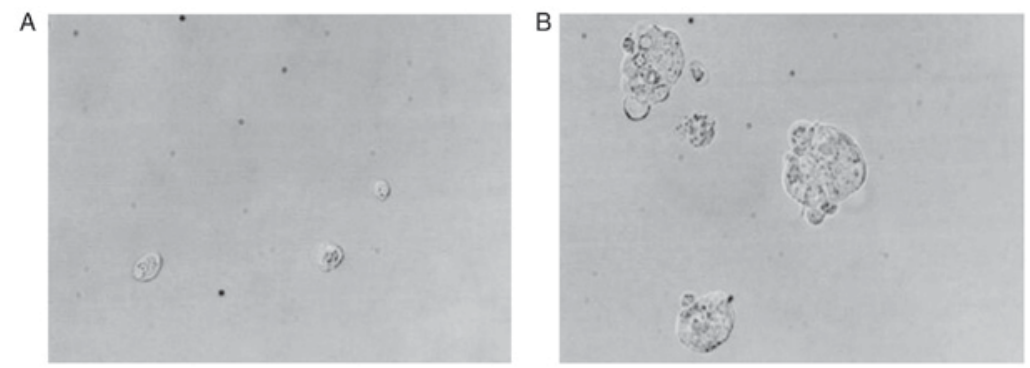

Figure 5. Isolation and culture of BCSCs after CD44+/CD24-/low sorting (x200). (A) 3 days; (B) 7 days.

suspended in the culture medium during the first 3 days of culture. After 7 days, small colonies could be observed, which increased in volume significantly after the culture medium was changed once every day (Fig. 5).

Detection of $\mathrm{CD} 105^{+}$and $\mathrm{CD}^{+} \mathrm{1}^{+}$cells. The percentage of $\mathrm{CD} 105^{+}$and $\mathrm{CD}^{+} 1^{+}$cells in the mammary gland was $4.5 \pm 0.9$ and $6.2 \pm 1.3 \%$, respectively (Fig. 6A and B). After continuous culturing in the endothelial cell culture system for three generations, the proportion of $\mathrm{CD} 105^{+}$and $\mathrm{CD} 31^{+}$ cells increased to $79.6 \pm 9.3$ and $84.1 \pm 10.7 \%$, respectively (Fig. 6C a D).

Functional detection of endothelial cells. Cells cultured in the endothelial cell culture medium phagocytosed DiL-Ac-LDL, which was demonstrated by the cells exhibiting red fluorescence. This suggested that the cells were functional endothelial cells. In contrast, the cells in the control group did not display red fluorescence (Fig. 7).

Angiogenesis. Cultured cells were seeded into 24-well plates together with adipocytes as the control. The endothelial cells displayed microscopic vascular-like structures that formed $24 \mathrm{~h}$ after culture, but the control cells showed no such morphology (Fig. 8).

\section{Discussion}

$\mathrm{BC}$ is one of the most common malignancies in women, and its incidence rate is the second highest in the world (18-20). Despite the existence of tumor stem cells in a variety of solid tumors and hematologic malignancies, there are presently many problems to be solved $(21,22)$. CSCs has the potential of self-renewal and multi-directional differentiation, which can differentiate into tumor parenchyma cells or tumor stromal cells. Recently, it has been found that the CD133(+) stem-like cell fraction is multipotent and capable of differentiation along tumor and endothelial lineages, since EPC was also found in glioma by differentiation of cancer stem cells. The capacity to generate tumour vasculature of the cancer stem cells within glioblastoma are novel findings, as well as the mechanisms of tumor neo-angiogenesis. that provide new insight into the biology of gliomas and the definition of cancer stemness, which may be far more than glioblastoma (23). Studies have shown that the endothelial cells derived from a variety of tissues participate in the process of tumor angiogenesis in BC (6). Therefore, we investigated whether BCSCs-derived endothelial cells likewise participate in tumor angiogenesis.

The results showed that the expression of CD31, VEGF, and mutant p53 was observable in paraffin-embedded sections of $\mathrm{BC}$ tissues. These cells were arranged along the vascular lumen or in vascular spheres. Furthermore, immunofluorescence and FISH also showed that the tumor cells expressed CD31 and HER2. CD31 localizes to the cell junctions of endothelial cells, and it is widely distributed in vascular cells. CD31 participates in a variety of physiological processes, such as angiogenesis; therefore, its expression is an indicator of in vivo angiogenesis (24). VEGF is a pro-angiogenic factor that promotes tumor angiogenesis. It also plays an important role in the proliferation of endothelial cells (25). Wild-type p53 functions as a tumor suppressor. However, mutant p53 inactivates the p53 gene, leading to tumorigenesis. At the same time, it has been found that the high expression of mutant p53 is very important in intratumoral angiogenesis (26). Therefore, the expression levels of CD31, VEGF, and p53 can be used as indicators of tumor vascular endothelial cells. The HER2 gene is a proto-oncogene, which is expressed at low levels in normal tissues, but is overexpressed or ectopically expressed in epithelium-derived tumor tissues such as breast cancer. It has been shown that HER2 expression is closely associated with the recurrence, metastasis, and poor prognosis of $\mathrm{BC}$ (27). FISH can detect the expression of the HER2 gene in BC tissue, which can help clarify the 

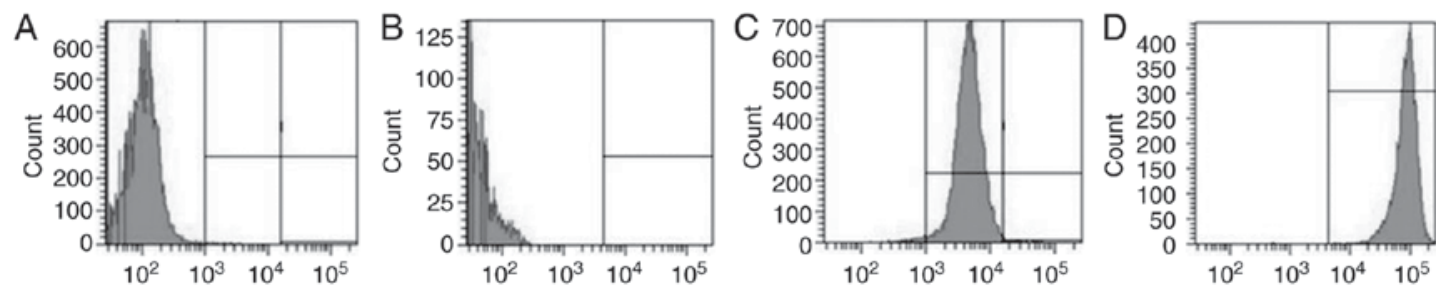

Figure 6. $\mathrm{CD} 105^{+}$and $\mathrm{CD} 31^{+}$cell ratios before and after culture. (A) $\mathrm{CD} 105^{+}$ratio; (B) $\mathrm{CD} 31^{+}$ratio; (C) $\mathrm{CD} 105^{+}$ratio; (D) $\mathrm{CD} 31^{+}$ratio.
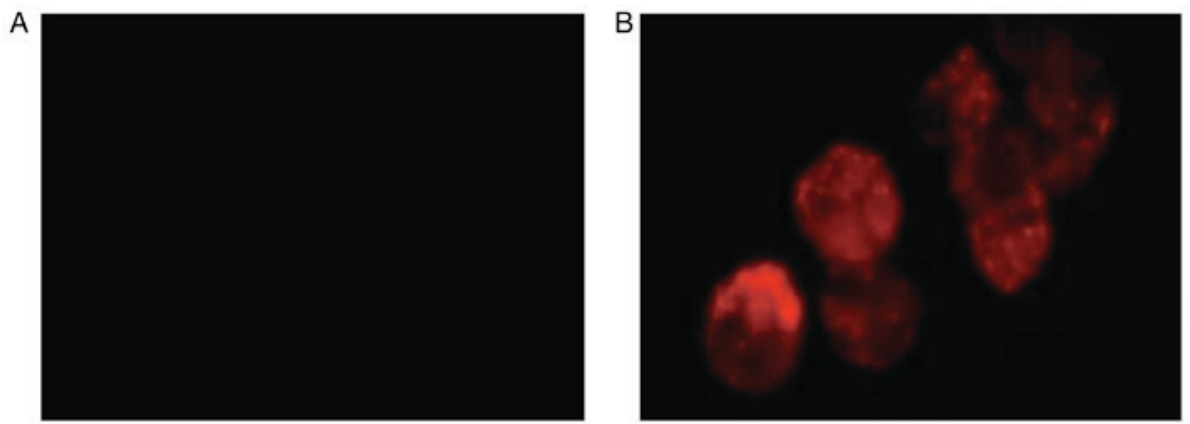

Figure 7. The red fluorescence signal stained by DiL-Ac-LDL, showed the phagocytosis of endothelial cells (x400). (A) Control group; (B) endothelial cells.
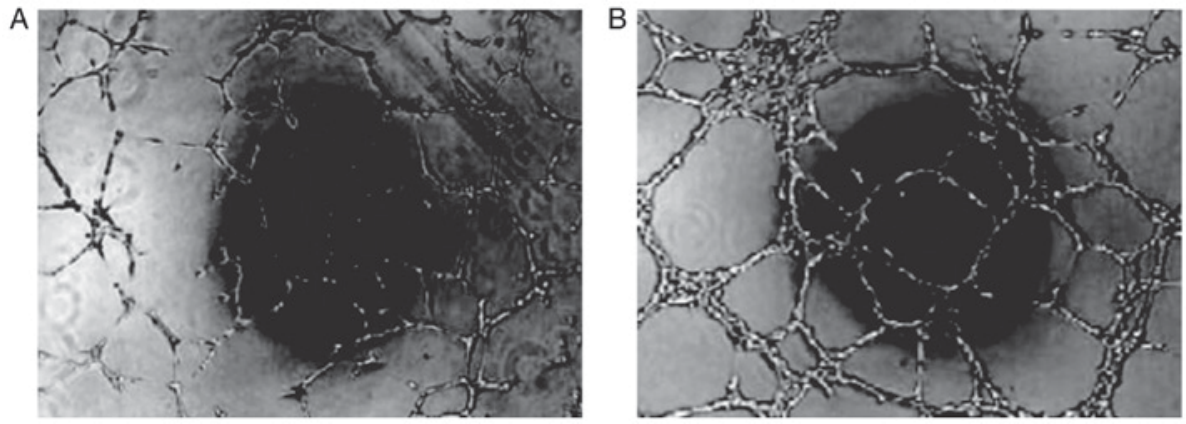

Figure 8. Angiogenesis using in vitro 3D gel culture (x40). (A) Control group; (B) endothelial cells.

relationship of chromosomes with gene and protein expression levels. The results of this study showed that the expressions of CD31 and HER2 in BC vascular cells confirmed the presence of tumor-derived endothelial cells in $\mathrm{BC}$ vessels. Moreover, some endothelial cells in BC have tumor homology.

CD24 is typically expressed in a variety of tumor cells. $\mathrm{CD} 24^{+}$cells display significantly enhanced tumorigenesis and metastasis, but the expression is downregulated in invasive BC. In contrast, $\mathrm{CD} 24^{-}$cells show biological characteristics associated with BCSCs (28). CD44 is upregulated in various tumor cells, including BC cells. Studies have shown that the overexpression of CD44 promotes tumor invasion and metastasis. Another study has shown that CD44 is an important marker of BCSCs (29). Therefore, many researchers in China and abroad isolate $\mathrm{CD} 44^{+} / \mathrm{CD} 24^{-}$cells during sorting, which are considered bona fide BCSCs. In this study, BCSCs were sorted using the immunomagnetic sorting method. The results showed that $\mathrm{CD} 44^{+}$cells comprised about $7.5 \pm 2.6 \%$ of the total cell population before sorting, and this increased to about $94.3 \pm 4.7 \%$ after sorting. In contrast, $\mathrm{CD} 24^{+}$cells constituted $48.2 \pm 9.4 \%$ of the total cell population before sorting and $4.3 \pm 1.6 \%$ after sorting, indicating that lower the abundance of $\mathrm{CD} 24^{+}$cells, higher is the amount of CD24-low cells. These results showed that immunomagnetic sorting enriched for $\mathrm{CD} 44^{+} / \mathrm{CD} 24^{-/ \text {low }}$ cells with high purity. The sorted cell suspension could form BC cell clusters after in vitro culture, indicating that they possessed tumor stem cell-like proliferation abilities. Meanwhile, the cells cultured in the endothelial differentiation culture system could internalize DiL-Ac-LDL, demonstrating their endothelial cell-like physiology.

Like CD34, CD31 is a pan-vascular endothelium marker. It cannot distinguish whether vascular endothelial cells are proliferating or not. In contrast, CD105 is present on the surface of endothelial cells and is specifically expressed in proliferating neovascular endothelial cells. Thus, CD105 is considered the best marker of neovascularization (30). In this study, mammary gland cells were digested, cultured in the EGM-2 endothelial cell culture system, and the 3rd-generation cells were collected for flow cytometry. The results showed that the $\mathrm{CD} 105^{+}$and $\mathrm{CD} 31^{+}$cells from the mammary gland comprised $4.5 \pm 0.9$ and $6.2 \pm 1.3 \%$ of the total population, respectively. In the 3rd-generation cells, this increased significantly to $79.6 \pm 9.3$ and 
$84.1 \pm 10.7 \%$, respectively, suggesting that BCSCs may differentiate into endothelial cells in the endothelial cell culture system. Meanwhile, the in vitro 3D gel culture experiments revealed vascular-like structures in cells differentiated and cultured from endothelial cells, confirming that endothelial cells differentiated from BCSCs have the ability to form vessels.

In summary, we believe that BCSCs-derived endothelial cells can differentiate into vascular endothelial cells and participate in tumor angiogenesis in vitro.

\section{Acknowledgements}

This study was supported by the President Fund of Liaoning Medical College-Clinical Medicine Construction Special Fund (No. XZJJ20140215).

\section{References}

1. Hong CS, Graham NA, Gu W, Espindola Camacho C, Mah V, Maresh EL, Alavi M, Bagryanova L, Krotee PA, Gardner BK, et al: MCT1 modulates cancer cell pyruvate export and growth of tumors that co-express MCT1 and MCT4. Cell Rep 14: 1590-1601, 2016.

2. Liu R, Shi P, Nie Z, Liang H, Zhou Z, Chen W, Chen H, Dong C, Yang R, Liu S and Chen C: Mifepristone suppresses basal triple-negative breast cancer stem cells by down-regulating KLF5 expression. Theranostics 6: 533-544, 2016.

3. Zhang J, Liu D, Feng Z, Mao J, Zhang C, Lu Y, Li J, Zhang Q, Li Q and Li L: MicroRNA-138 modulates metastasis and EMT in breast cancer cells by targeting vimentin. Biomed Pharmacother 77: 135-141, 2016.

4. Telang N: Putative cancer-initiating stem cells in cell culture models for molecular subtypes of clinical breast cancer. Oncol Lett 10: 3840-3846, 2015.

5. Zhu A, Li Y, Song W, Xu Y, Yang F, Zhang W, Yin Y and Guan X: Antiproliferative Effect of Androgen Receptor Inhibition in Mesenchymal Stem-Like Triple-Negative Breast Cancer. Cell Physiol Biochem 38: 1003-1014, 2016.

6. Schulenburg A, Blatt K, Cerny-Reiterer S, Sadovnik I, Herrmann H, Marian B, Grunt TW, Zielinski CC and Valent P: Cancer stem cells in basic science and in translational oncology: can we translate into clinical application? J Hematol Oncol 8: 16, 2015.

7. Xu L, Zhang L, Hu C, Liang S, Fei X, Yan N, Zhang Y and Zhang F: WNT pathway inhibitor pyrvinium pamoate inhibits the self-renewal and metastasis of breast cancer stem cells. Int J Oncol 48: 1175-1186, 2016.

8. Yu J, Zhang Y, Leung LH, Liu L, Yang F and Yao X: Efficacy and safety of angiogenesis inhibitors in advanced gastric cancer: A systematic review and meta-analysis. J Hematol Oncol 18: 111, 2016.

9. Goel G and Sun W: Ramucirumab, another anti-angiogenic agent for metastatic colorectal cancer in second-line setting-its impact on clinical practice. J Hematol Oncol 8: 92, 2015.

10. Trivanović D, Jauković A, Krstić J, Nikolić S, Okić Djordjević I, Kukolj T, Obradović H, Mojsilović S, Ilić V, Santibanez JF and Bugarski D: Inflammatory cytokines prime adipose tissue mesenchymal stem cells to enhance malignancy of MCF-7 breast cancer cells via transforming growth factor- 31 . IUBMB Life 68: 190-200, 2016.

11. Kasimir-Bauer S, Bittner AK, König L, Reiter K, Keller T, Kimmig $\mathrm{R}$ and Hoffmann O: Does primary neoadjuvant systemic therapy eradicate minimal residual disease? Analysis of disseminated and circulating tumor cells before and after therapy. Breast Cancer Res 18: 20, 2016.

12. Mori M, Ito F, Shi L, Wang Y, Ishida C, Hattori Y, Niwa M, Hirayama T, Nagasawa H, Iwase A, et al: Ovarian endometriosis-associated stromal cells reveal persistently high affinity for iron. Redox Biol 6: 578-586, 2015.
13. Kanwar JR, Kamalapuram SK, Krishnakumar S and Kanwar RK: Multimodal iron oxide (Fe3O4)-saturated lactoferrin nanocapsules as nanotheranostics for real-time imaging and breast cancer therapy of claudin-low, triple-negative (ER(-)/PR(-)/HER2(-)). Nanomedicine (Lond) 11: 249-268, 2016.

14. Sharma B, Varney ML, Saxena S, Wu L and Singh RK: Induction of CXCR2 ligands, stem cell-like phenotype, and metastasis in chemotherapy-resistant breast cancer cells. Cancer Lett 372: 192-200, 2016.

15. Xie J, Liu J, Liu H, Liang S, Lin M, Gu Y, Liu T, Wang D, Ge H and Mo SL: The antitumor effect of tanshinone IIA on anti-proliferation and decreasing VEGF/VEGFR2 expression on the human non-small cell lung cancer A549 cell line. Acta Pharm Sin B 5: 554-563, 2015.

16. Botelho MC and Alves $\mathrm{H}$ : Endothelial progenitor cells in breast cancer. Int J Immunother Cancer Res 2: 1-2, 2016.

17. Teng L, Peng S, Guo H, Liang H, Xu Z, Su Y and Gao L: Conditioned media from human ovarian cancer endothelial progenitor cells induces ovarian cancer cell migration by activating epithelial-to-mesenchymal transition. Cancer Gene Ther 22: 518-523, 2015

18. Amoury M, Kolberg K, Pham AT, Hristodorov D, Mladenov R, Di Fiore S, Helfrich W, Kiessling F, Fischer R, Pardo A, et al: Granzyme B-based cytolytic fusion protein targeting EpCAM specifically kills triple negative breast cancer cells in vitro and inhibits tumor growth in a subcutaneous mouse tumor model. Cancer Lett 372: 201-209, 2016.

19. Kong L, Guo S, Liu C, Zhao Y, Feng C, Liu Y, Wang T and Li C: Overexpression of SDF-1 activates the NF- $\kappa B$ pathway to induce epithelial to mesenchymal transition and cancer stem cell-like phenotypes of breast cancer cells. Int J Oncol 48: 1085-1094, 2016.

20. Liu Y, Zou T, Wang S, Chen H, Su D, Fu X, Zhang Q and Kang X: Genistein-induced differentiation of breast cancer stem/progenitor cells through a paracrine mechanism. Int J Oncol 48: 1063-1072, 2016.

21. Yin X, Zhang BH, Zheng SS, Gao DM, Qiu SJ, Wu WZ and Ren ZG: Coexpression of gene Oct4 and Nanog initiates stem cell characteristics in hepatocellular carcinoma and promotes epithelial-mesenchymal transition through activation of Stat3/Snail signaling. J Hematol Oncol 8: 23, 2015.

22. Chen Y, Cang S, Han L, Liu C, Yang P, Solangi Z, Lu Q, Liu D and Chiao JW: Establishment of prostate cancer spheres from a prostate cancer cell line after phenethyl isothiocyanate treatment and discovery of androgen-dependent reversible differentiation between sphere and neuroendocrine cells. Oncotarget 7: 26567-26579, 2016.

23. Wang R, Chadalavada K, Wilshire J, Kowalik U, Hovinga KE, Geber A, Fligelman B, Leversha M, Brennan C and Tabar V: Glioblastoma stem-like cells give rise to tumour endothelium. Nature 468: 829-833, 2010.

24. Liu L, Tong Q, Liu S, Cui J, Zhang Q, Sun W and Yang S: ZEB1 Upregulates VEGF Expression and Stimulates Angiogenesis in Breast Cancer. PLoS One 11: e0148774, 2016.

25. De Francesco EM, Pellegrino M, Santolla MF, Lappano R, Ricchio E, Abonante S and Maggiolini M: GPER mediates activation of HIF1 $\alpha /$ VEGF signaling by estrogens. Cancer Res 74: 4053-4064, 2014.

26. Jaeger S, Min J, Nigsch F, Camargo M, Hutz J, Cornett A, Cleaver S, Buckler A and Jenkins JL: Causal Network Models for Predicting Compound Targets and Driving Pathways in Cancer. J Biomol Screen 19: 791-802, 2014.

27. Lekovic G, Drazin D, Mak AC and Schwartz MS: Cyberknife radiosurgery and concurrent intrathecal chemotherapy for leptomeningeal metastases: Case report of prolonged survival of a HER-2 ${ }^{+}$breast cancer patient status-post craniospinal irradiation. Cureus 8: e453, 2016.

28. Suyama K, Onishi H, Imaizumi A, Shinkai K, Umebayashi M, Kubo M, Mizuuchi Y, Oda Y, Tanaka M, Nakamura M and Katano M: CD24 suppresses malignant phenotype by downregulation of SHH transcription through STAT1 inhibition in breast cancer cells. Cancer Lett 374: 44-53, 2016.

29. Gangopadhyay S, Nandy A, Hor P and Mukhopadhyay A: Breast cancer stem cells: A novel therapeutic target. Clin Breast Cancer 13: $7-15,2013$.

30. Park MT, Oh ET, Song MJ, Kim WJ, Cho YU, Kim SJ, Han JY, Suh JK, Choi EK, Lim BU, et al: The radiosensitivity of endothelial cells isolated from human breast cancer and normal tissue in vitro. Microvasc Res 84: 140-148, 2012. 